\title{
A Novel X-Ray Radiation Sensor Based on Networked $\mathrm{SnO}_{2}$ Nanowires
}

\author{
Jae-Hun Kim ${ }^{1}{ }^{\circledR}$, Ali Mirzaei ${ }^{2,3}{ }^{\circledR}$, Hyoun Woo Kim ${ }^{2,4, *}$, Hong Joo Kim ${ }^{5, *}$, Phan Quoc Vuong ${ }^{5}$ \\ and Sang Sub Kim ${ }^{1, * \mathbb{D}}$ \\ 1 Department of Materials Science and Engineering, Inha University, Incheon 22212, Korea; \\ kjhhb5331@gmail.com \\ 2 The Research Institute of Industrial Science, Hanyang University, Seoul 04763, Korea; \\ alisonmirzaee@yahoo.com \\ 3 Department of Materials Science and Engineering, Shiraz University of Technology, Shiraz 71557-13876, Iran \\ 4 Division of Materials Science and Engineering, Hanyang University, Seoul 04763, Korea \\ 5 Department of Physics, Kyungpook National University, 80 Daehakro, Bukgu, Daegu 41566, Korea; \\ vuong.pvl@gmail.com \\ * Correspondence: hyounwoo@hanyang.ac.kr (H.W.K.); hongjoo@knu.ac.kr (H.J.K.); \\ sangsub@inha.ac.kr (S.S.K.)
}

Received: 15 October 2019; Accepted: 11 November 2019; Published: 14 November 2019

\begin{abstract}
X-Ray radiation sensors that work at room temperature are in demand. In this study, a novel, low-cost real-time $\mathrm{X}$-ray radiation sensor based on $\mathrm{SnO}_{2}$ nanowires (NWs) was designed and tested. Networked $\mathrm{SnO}_{2} \mathrm{NWs}$ were produced via the vapor-liquid-solid technique. X-ray diffraction (XRD), transmission electron microscopy (TEM) and field emission scanning electron microscopy (SEM) analyses were used to explore the crystallinity and morphology of synthesized $\mathrm{SnO}_{2} \mathrm{NWs}$. The fabricated sensor was exposed to X-rays $(80 \mathrm{kV}, 0.0-2.00 \mathrm{~mA})$ and the leakage current variations were recorded at room temperature. The $\mathrm{SnO}_{2} \mathrm{NWs}$ sensor showed a high and relatively linear response with respect to the $\mathrm{X}$-ray intensity. The $\mathrm{X}$-ray sensing results show the potential of networked $\mathrm{SnO}_{2} \mathrm{NWs}$ as novel X-ray sensors.
\end{abstract}

Keywords: $\mathrm{SnO}_{2}$; nanowire; radiation; $\mathrm{X}$-ray sensors

\section{Introduction}

Radiation can be broadly divided into two categories: uncharged radiation, including X-rays, gamma rays, and neutrons; charged radiation, including electrons, positrons (beta particles), and alpha particles [1]. Radiation sensors are able to transform the energy lost by an incident particle into an electrical signal, which is then processed by electronic techniques. Metal oxides (MOs) are among the most commonly used materials for advanced applications due to their availability, low cost, simple synthesis procedures and flexible morphology and composition [2]. Accordingly, many researchers have used these materials for different applications, ranging from catalysts [3] to sensors [4-7].

In particular, they can be used for high-energy radiation sensors. In fact, the radiations with a high energy like gamma rays and X-rays can alter the concentration of oxygen vacancies and also create point defects and other structural defects in MOs [8]. Therefore, metal oxides can be used for the detection of high-energy radiation [9].

Today, low-cost radiation sensors based on MOs operating at room temperature are sought after for applications in science, industry, medicine and security [10]. Additionally, unpredictable accidents may occur during the storage or transportation of radioactive materials, which highlights the needs for metal oxide radiation sensors. 
A radiation sensor should have a high sensitivity, a linear performance and an on-line response, low levels of noise and high reliability [11]. Based on the above criteria, a number of MOs were suggested for gamma ray sensing $[12,13]$. For example, it has been reported that the electrical properties of $\mathrm{TeO}_{2}$ and many other MOs greatly change after gamma ray bombardment [14]. Although X-rays can also affect the structural properties of MOs, there are few reports about $\mathrm{X}$-ray radiation sensors based on MOs in the literature [15-17].

$\mathrm{SnO}_{2}$ is a well-known n-type semiconducting metal oxide $(\mathrm{Eg}=3.8 \mathrm{eV})$. It has a high mobility of electrons $\left(160 \mathrm{~cm}^{2} / \mathrm{Vs}\right)$, high physical and chemical stability, a high availability and a low price [18]. Therefore, it has been used in many applications, including gas sensors [19], lithium ion batteries [20], photodetectors [21] and electrodes [22]. Therefore, different methods, such as the vapor-liquid-solid (VLS) technique [23,24], colloidal synthesis [25], chemical vapor deposition [26,27] and hydrothermal [28] have been used for the preparation of $\mathrm{SnO}_{2}$ nanowires (NWs). Among them, the VLS method has advantages, such as simplicity, low price and the possibility of control over the $\mathrm{SnO}_{2}$ NWs. Generally, the length of NWs depends on the growth time, and the NW's diameter is determined by the size of the metal catalyst droplets [29].

In this study, we prepared networked $\mathrm{SnO}_{2} \mathrm{NWs}$ and measured their capability to detect $\mathrm{X}$-ray radiation at room temperature. Although networked NWs are very common for gas sensing studies [30,31], there is no report on their X-ray sensing capabilities. To the best of our knowledge, this is the first study reporting $\mathrm{X}$-ray radiation sensing using networked $\mathrm{SnO}_{2} \mathrm{NWs}$. From a sensing response and performance standpoint, networked NWs sensors are potential candidates for radiation sensors because their carrier lifetime is enhanced significantly due to the reduction in defect density on the surface passivated NWs [32]. The results obtained demonstrate the effective sensing capability of $\mathrm{SnO}_{2} \mathrm{NWs}$ as X-ray sensors. The sensing mechanism is explained in detail.

\section{Materials and Methods}

\subsection{Synthesis of Networked $\mathrm{SnO}_{2} \mathrm{NWs}$}

We used the vapor-liquid-solid (VLS) technique for the selective growth of networked $\mathrm{SnO}_{2}$ NWs, described in detail in earlier reports of the present authors [33-35]. To this end, tri-layered interdigitated electrodes comprising of $\mathrm{Au}(3 \mathrm{~nm}), \mathrm{Pt}(100 \mathrm{~nm})$ and $\mathrm{Ti}(100 \mathrm{~nm})$ were deposited by a sputtering process on $\mathrm{SiO}_{2}$-grown $\mathrm{Si}$ substrates. The Au top layer served as a catalytic layer for the selective growth of $\mathrm{SnO}_{2} \mathrm{NWs}$. Then, the substrates were put into a quartz-tube furnace, where an $\mathrm{Al}_{2} \mathrm{O}_{3}$ crucible containing highly pure metallic Sn powders (Sigma-Aldrich, St. Louis, MO, USA, 99.9\%) was placed. Afterwards, the furnace was then evacuated using a rotary pump down to a pressure of 1 $\times 10^{-3}$ Torr and was heated $\left(10^{\circ} \mathrm{C} / \mathrm{min}\right)$ to $900^{\circ} \mathrm{C}$ in the presence of $\mathrm{N}_{2}$ and $\mathrm{O}_{2}$ gases with flow rates of 300 and $10 \mathrm{sccm}$, respectively. After keeping at this temperature for $15 \mathrm{~min}$, networked $\mathrm{SnO}_{2} \mathrm{NWs}$ were successfully grown on the substrate.

\subsection{Characterization}

The morphology of the $\mathrm{SnO}_{2} \mathrm{NWs}$ was studied by field-emission scanning electron microscopy (FE-SEM, Hitachi-S-4200, Hitach, Ltd., Tokyo, Japan). Transmission electron microscopy (TEM) was also used to further investigate the morphology of the synthesized product. X-ray diffraction (XRD, Xpert MPD PRO, Philips, The Netherlands) with CuK $\alpha$ radiation $(\lambda=1.540 \AA)$ was employed to study the phase and crystalline structure of the synthesized $\mathrm{SnO}_{2} \mathrm{NWs}$.

\subsection{X-Ray Sensing studies}

An X-ray tube from DRGEM Co., Ltd, Gwangmyeong, Korea. with different currents was used to irradiate the fabricated sensor. The X-ray-induced current was measured by a high-resistance electrometer, a KEITHLEY 6517, versus bias applied voltage which was applied between the interdigitated electrodes, before and after exposure to X-rays. The fabricated sensor was held 
near the outlet of the X-ray tube where the X-ray intensity was highest. During the X-ray irradiation experiments, temperature and humidity were held constant. Figure 1a shows a digital photograph of the set up for sensing and Figure $1 \mathrm{~b}$ schematically shows the $\mathrm{X}$-ray sensing procedure.
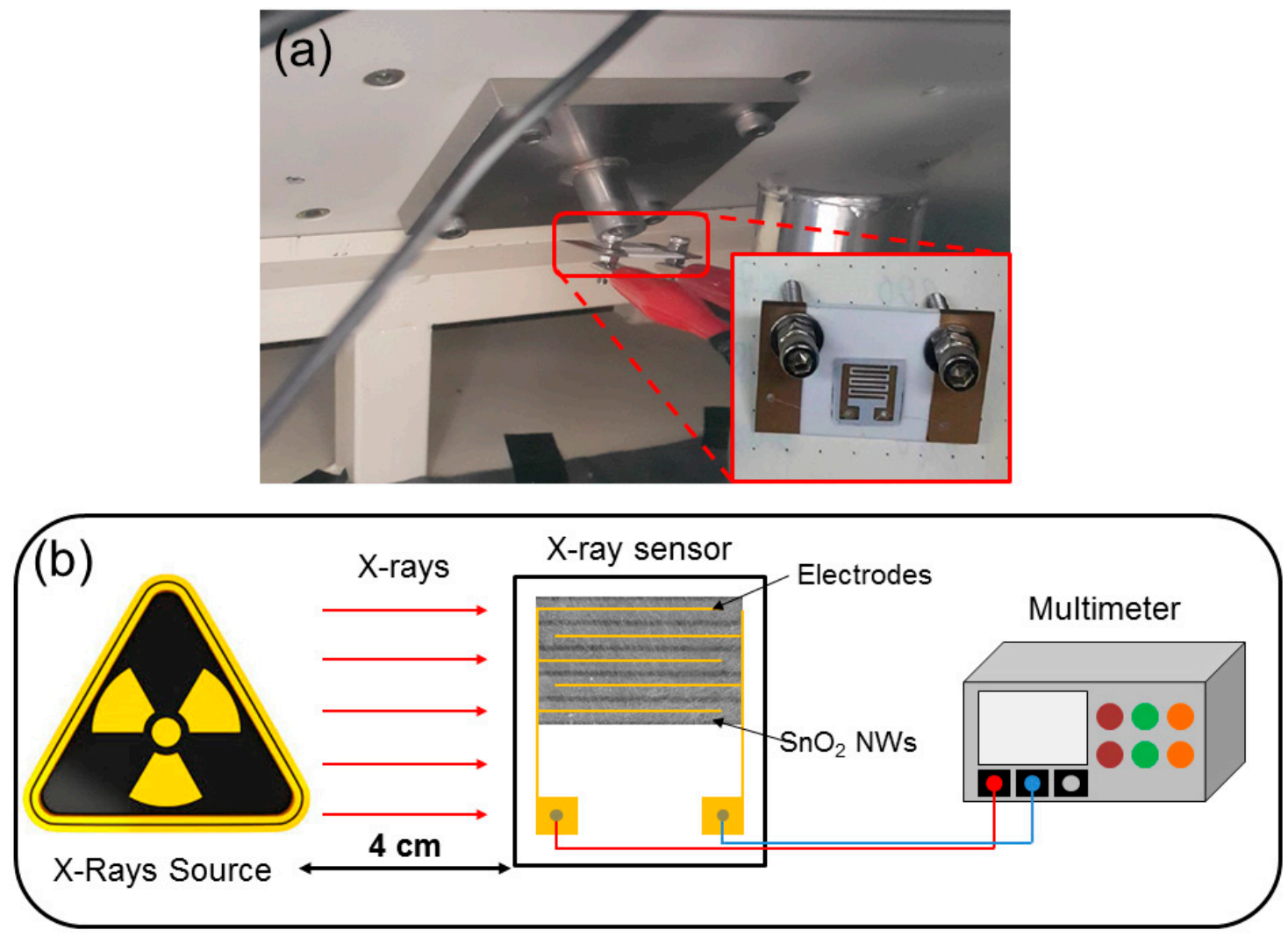

Figure 1. (a) Digital photograph of the set up for sensing. (Inset: X-ray sensor). (b) Schematic showing the set up for X-ray sensing.

\section{Results and Discussion}

\subsection{Growth of Networked $\mathrm{SnO}_{2} \mathrm{NWs}$}

$\mathrm{SnO}_{2} \mathrm{NWs}$ were fabricated using the Au-catalyzed vapor-liquid-solid (VLS) growth method. In this process, ultrafine Au nanoparticles (NPs) were deposited on the $\mathrm{Si}$ substrate on which $\mathrm{SnO}_{2}$ NWs were grown. Sn vapors coming from the Sn source were first carried and condensed on the substrate and with the $\mathrm{Au}$ formed an alloy and liquefied. With a decrease in temperature and in the presence of flowing oxygen, the $\mathrm{SnO}_{2}$ crystals nucleated at the liquid-solid interface and further condensation/dissolution of $\mathrm{Sn}$ vapor increased the amount of $\mathrm{SnO}_{2}$ crystal precipitation from the alloy. The incoming Sn species preferred to diffuse to and condense at the existing solid-liquid interface because of the lower levels of energy involved with the crystal step growth as compared with secondary nucleation events in a finite volume. As a result, no new solid-liquid interfaces were formed, and the interface was pushed to form a $\mathrm{SnO}_{2} \mathrm{NW}$. After the system completely cooled, the alloy droplets solidified on the $\mathrm{SnO}_{2}$ NWs tips [36-38].

\subsection{Morphological and Structural Analyses}

Figure 2 shows a representative XRD pattern taken from networked $\mathrm{SnO}_{2} \mathrm{NWs}$. All the peaks located at $2 \theta=26.55,33.85,51.85,54.75,61.75,64.85$ and $65.95^{\circ}$ can be indexed as the (110), (101), (211), (220), (301), (112), and (311) planes of $\mathrm{SnO}_{2}$, respectively, with a tetragonal rutile structure (JCPDS Card No. 88-0287) [39]. The high intensity of the $\mathrm{SnO}_{2}$ Bragg peaks demonstrates the highly crystalline nature of the synthesized $\mathrm{SnO}_{2} \mathrm{NWs}$. 


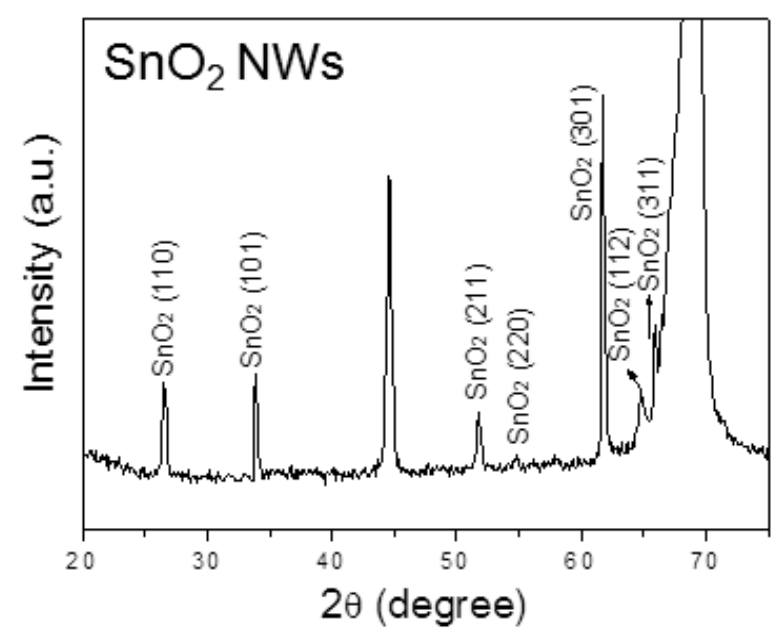

Figure 2. Representative X-ray diffraction (XRD) pattern of $\mathrm{SnO}_{2}$ nanowires (NWs).

In Figure 3a-c, FE-SEM micrographs with different magnifications are provided. It is evident that NWs are grown selectively on interdigitated electrodes due to the catalytic activity of Au. In particular, Figure 3 a indicates a plan-view low-magnified FE-SEM micrograph of networked $\mathrm{SnO}_{2} \mathrm{NWs}$, showing a selective growth of $\mathrm{SnO}_{2}$ NWs. Figure 3b shows a higher magnification image, where long $\mathrm{SnO}_{2}$ NWs with a relatively dense structure and a straight-line morphology can be seen. Figure 3c clearly shows the formation of ultrathin $\mathrm{SnO}_{2} \mathrm{NWs}$, where the diameter of the $\mathrm{SnO}_{2} \mathrm{NWs}$ is estimated to be 50-60 nm.

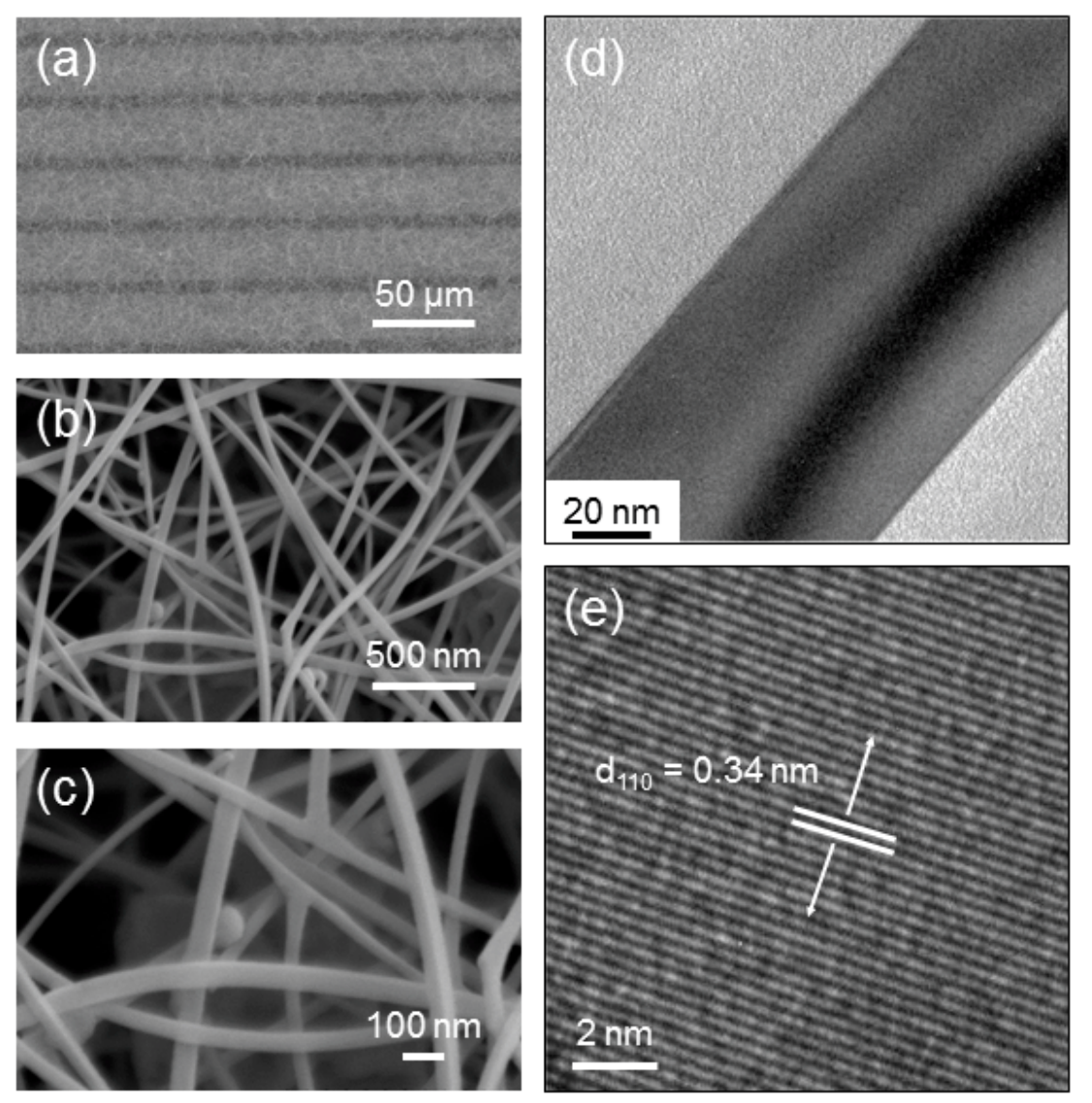

Figure 3. (a-c) Field-emission scanning electron microscopy (FE-SEM) micrographs of $\mathrm{SnO}_{2}$ NWs with different magnifications. Transmission electron microscopy (TEM) analyses results; (d) low-magnification bright-field TEM image; (e) high-resolution lattice image. 
To further examine the crystalline quality of synthesized NWs, TEM analysis was performed. A low-magnification bright-field image of a single NW is presented in Figure 3d. Obviously, the NW is very smooth at the surface and has a single-crystalline nature without any defects, including stacking faults or dislocations. The high-resolution lattice micrograph, presented in Figure 3e, again demonstrates the single-crystalline quality. The spacing between the parallel fringes is $\sim 0.340 \mathrm{~nm}$, which can correspond to the (110) plane of $\mathrm{SnO}_{2}$ [40].

\subsection{Leakage Current and X-Ray Sensing Studies}

Similarly to visible-light photodetectors, which need a low leakage current to have a high signal-to-noise ratio, semiconductor-based $\mathrm{X}$-ray sensors must have low leakage currents to ensure their high sensitivity. Accordingly, before testing the X-ray radiation sensing capability of the $\mathrm{SnO}_{2} \mathrm{NWs}$, in order to have insight into the leakage current of a fabricated sensor, the typical I-V characteristics of $\mathrm{SnO}_{2} \mathrm{NWs}$ were studied. Figure 4a-d shows the FE-SEM images of $\mathrm{SnO}_{2} \mathrm{NWs}$ with different densities of $\mathrm{SnO}_{2} \mathrm{NWs}$ from the highest to the lowest densities, respectively, and corresponding leakage currents versus applied voltages are shown in Figure $4 \mathrm{e}-\mathrm{h}$, respectively. As can be seen, as the density of the $\mathrm{SnO}_{2} \mathrm{NWs}$ decreases, the leakage current increases. Therefore, for practical applications, the use of highly dense $\mathrm{SnO}_{2} \mathrm{NWs}$ will result in a better sensing performance and will enhance the signal to noise ratio. In particular, the sample with the highest density of $\mathrm{SnO}_{2} \mathrm{NWs}$ showed the lowest leakage current. This sample had a very low dark leakage current; for example, for bias voltages of 1 and $5 \mathrm{~V}$, the leakage currents were $\sim 0.25$ and $0.9 \mathrm{pA}$ respectively. These very low leakage currents enhance the signal to noise ratio for semiconductor radiation sensors. The leakage current of a semiconductor sensing material is strongly governed by the band gap energy and the structure of the sensing material. Large band gap materials, $>1.5 \mathrm{eV}$, are needed to maintain a low intrinsic carrier concentration and a low leakage current during sensor operation at room temperature. Additionally, the amount of carrier trapping centers must be extremely low. For example, regions near and along the cracks show much higher leakage current than regions away from the cracks [41]. Therefore, the low current leakages obtained for the fabricated sensor demonstrate the high quality of the synthesized $\mathrm{SnO}_{2} \mathrm{NWs}$ in this study.

To evaluate the X-ray sensing capability, the X-ray current response of the $\mathrm{SnO}_{2} \mathrm{NWs}$ sensor with respect to $X$-ray intensity was measured at room temperature, as shown in Figure 5 . During the measurements, the current of the $\mathrm{X}$-ray source was varied from 0 to $2 \mathrm{~mA}$ while the applied voltages for the $\mathrm{X}$-ray generator and sensor were kept constant at $80 \mathrm{kV}$ and $5 \mathrm{~V}$, respectively. The signal intensity was strong as compared to dark current and it was quite linear, as shown in Figure 5. Based on these results, we have a meaningful response of the $\mathrm{SnO}_{2} \mathrm{NWs}$ to X-ray radiation. For example, for X-ray currents of 1 and $2 \mathrm{~mA}$, the sensor currents were 65 and $120 \mathrm{pA}$ respectively, demonstrating the near-linearity of the response of the $\mathrm{SnO}_{2} \mathrm{NWs}$ sensor.

We also tested the conductivity of $\mathrm{SnO}_{2}$ NWs. Figure 6 shows current passing through the $\mathrm{SnO}_{2}$ NWs under a fixed voltage of $1 \mathrm{~V}$ over time. As can be seen, the $\mathrm{SnO}_{2} \mathrm{NW}$ sensor shows a stable signal over time, demonstrating its high stability for sensing applications. 

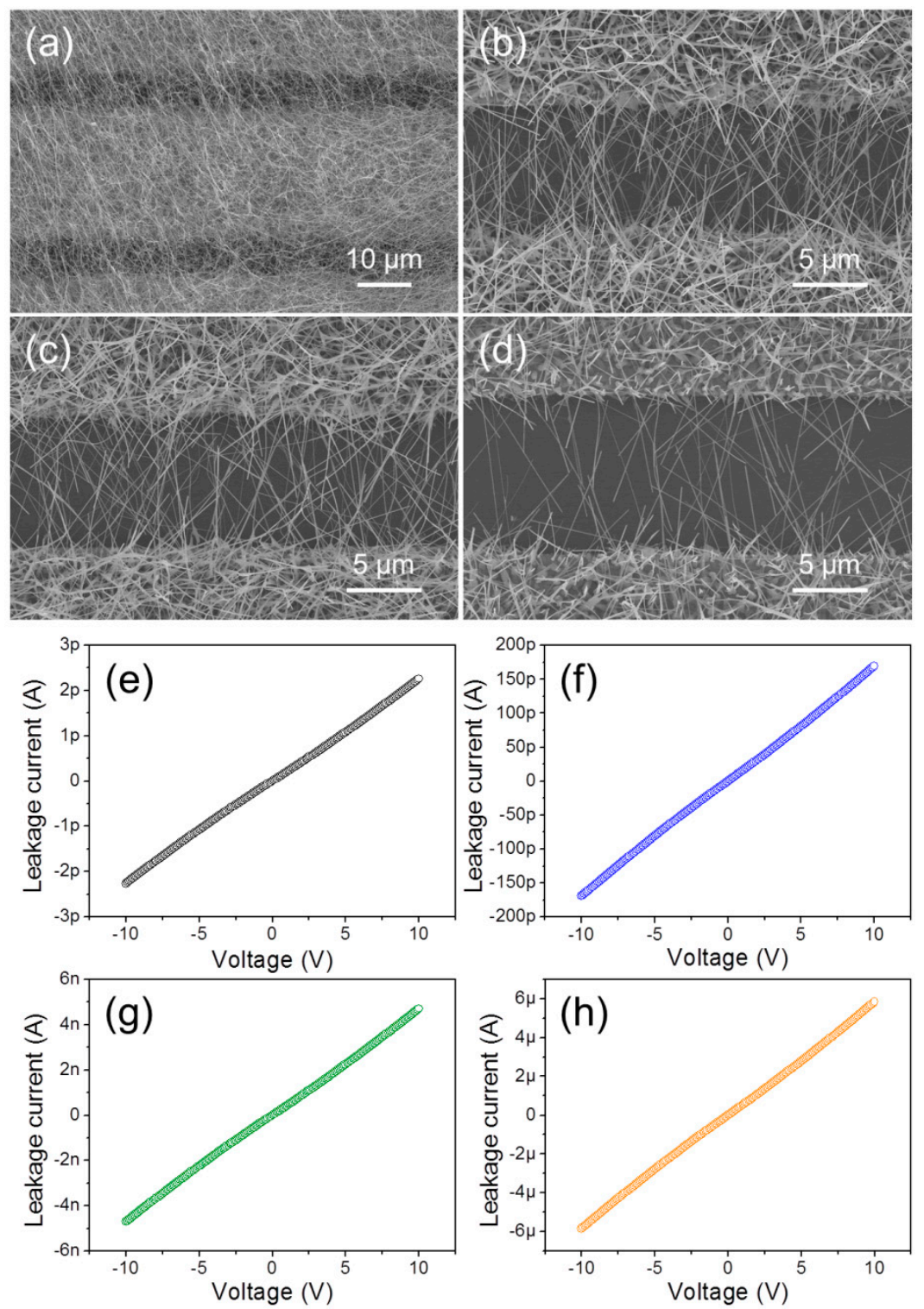

Figure 4. Scanning electron microscopy (SEM) images of $\mathrm{SnO}_{2} \mathrm{NWs}$ with different densities of NWs from (a), (b), (c) to (d) the highest density to the lowest density. (e)-(h) Corresponding leakage currents of $\mathrm{SnO}_{2} \mathrm{NWs}$ versus applied voltage.

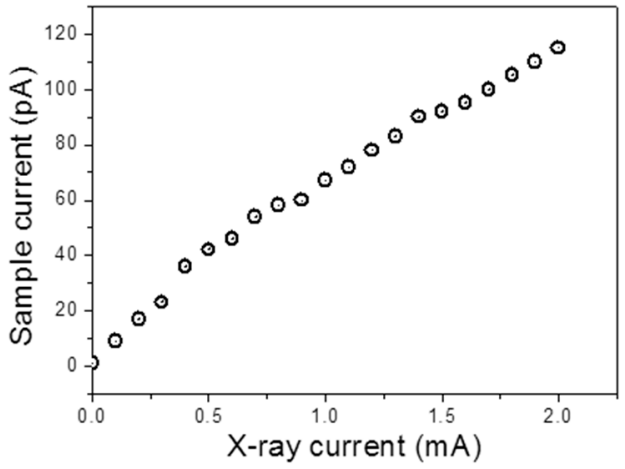

Figure 5. Dependence of the current response with respect to the intensity of the X-ray source under a constant applied voltage of $5 \mathrm{~V}$. 


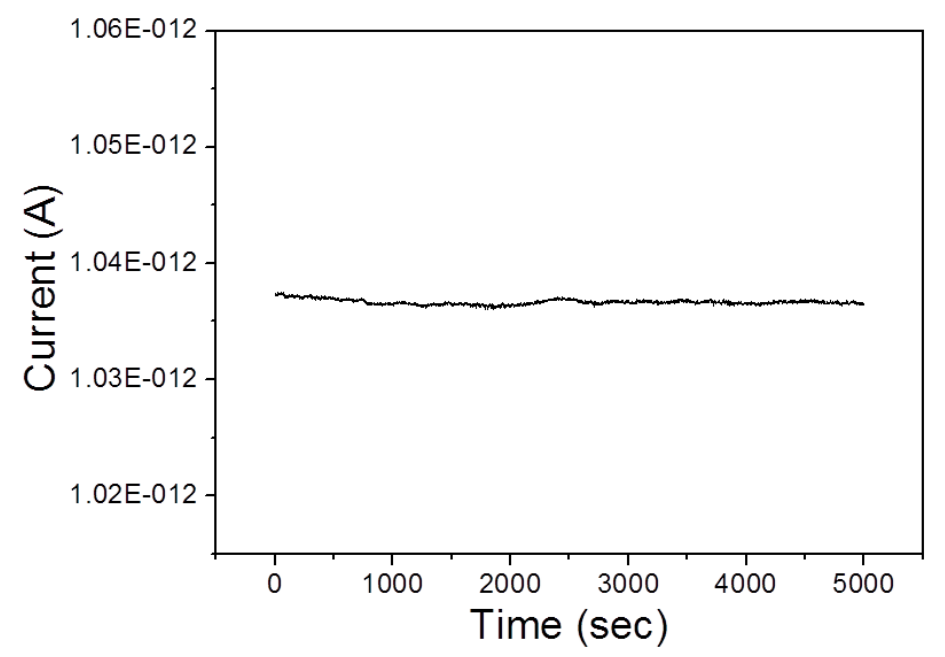

Figure 6. Current passing the $\mathrm{SnO}_{2} \mathrm{NWs}$ under a fixed voltage of $1 \mathrm{~V}$ versus the time.

\subsection{Sensing Mechanism}

In semiconductor radiation sensor operation, incident radiation creates a charge pulse consisting of electrons and holes within the detector, which are then separated using an applied electric field and the current is sensed by an external circuit. Electromagnetic radiation can interact with a material via different mechanisms [1]: (i) elastic scattering, (ii) photo-electric absorption, (iii) Compton scattering, and (iv) pair production. However, the dominant mechanism and the result of the interaction strongly depend on the incident energy of the interacting X-ray beam and the composition of the sensor [42]. In the case of elastic scattering, the energy of the incident photon is not changed and this process does not contribute to the deposition of energy on the sensor. Photoelectric absorption is the ideal process for sensor operation, where the incident photon loses all of its energy upon incident with the sensor material to one of the orbital electrons of the atoms of the sensor material. Subsequently, this photoelectron loses its kinetic energy through Columbic interactions and creates plenty of electron-hole pairs, which are subsequently separated by the electric field, and a current is produced [41,43]. During Compton scattering, which is a collision between an incident photon and an orbital electron, both the energy and the direction of the photons change. In fact, some of the energy will be lost to the electrons of the sensing material. These electrons will then lose their energy through the generation of electron-hole pairs. In Compton scattering, a photon does not transfer all of its energy to an electron. Accordingly, the number of electron-hole pairs generated varies remarkably between different Compton events [1]. In the pair production process, a photon with high energy interacts within the Coulomb field of the nucleus and directly produces an electron-positron pair. Generally, the photoelectric effect dominates in the energy range to $\sim 200 \mathrm{keV}$, the Compton effect to a few $\mathrm{MeV}$ and pair production above $\sim 6 \mathrm{MeV}$ [44].

The $\mathrm{SnO}_{2} \mathrm{NW}$ is a semiconductor material which can directly convert ionization radiation into an electrical signal. In this study, X-ray irradiation was used to demonstrate the radiation sensing capability of $\mathrm{SnO}_{2} \mathrm{NW}$. When an X-ray traverses the sensor, it may partly or fully transfer its energy to electrons via the photoelectric effect or Compton scattering [45]. These primary energetic electrons may cause an ionization cascade until their energy is in equilibrium with the energy band gap of the media. This leads to the creation of several electron-hole pairs in the sensor. Signal intensity strongly depends on the collection efficiency of these electron-hole pairs. The collection probability is in competition with electron-hole recombination, which is related to carrier lifetime or defect density.

\section{Conclusions}

In this study, networked $\mathrm{SnO}_{2} \mathrm{NWs}$ were fabricated by a VLS technique and were used for the detection of X-ray radiation at room temperature. XRD, TEM and FE-SEM characterizations approved the successful formation of NWs with the desired composition and morphology. The non-proportional 
response of the X-ray source was tested. The X-ray radiation sensing results show that the $\mathrm{SnO}_{2} \mathrm{NWs}$ sensors have promising sensing capability, where low leakage current was observed for the $\mathrm{SnO}_{2} \mathrm{NWs}$ sensor. Another strategy to reduce the defect density of the oxide NWs is to perform high-temperature annealing [45]. Stabilization studies of these sensors will also be conducted in future work.

Author Contributions: S.S.K., H.W.K. and H.J.K. conceived and designed the experiments and completed the paper; J.-H.K. and P.Q.V. performed the experiments; J.-H.K., Q.V.P. and A.M. analyzed the data and prepared the draft of the paper. All authors approved the final version of the paper.

Funding: This research was funded by the National Research Foundation of Korea (NRF) via a grant number 2018R1A6A1A06024970 and 2016R1A6A1A03013422 and APC was 100\% discounted.

Acknowledgments: This study was supported byInha University.

Conflicts of Interest: The authors declare no conflict of interest and the founding sponsors had no role in the design of the study; in the collection, analyses, or interpretation of data; in the writing of the manuscript, and in the decision to publish the results.

\section{References}

1. Schlesinger, T.E.; James, R.B. Semiconductors for Room Temperature Nuclear Applications, 1st ed.; Academic Pres: New York, NY, USA, 1995.

2. Arshak, K.; Korostynska, O.; Fahim, F. Various Structures Based on Nickel Oxide Thick Films as Gamma Radiation Sensors. Sensors 2003, 3, 176-186. [CrossRef]

3. Wei, Z.; Wei, X.; Wang, S.; He, D. Preparation and Visible-Light Photocatalytic Activity of $\alpha-\mathrm{Fe}_{2} \mathrm{O}_{3} / \gamma-\mathrm{Fe}_{2} \mathrm{O}_{3}$ Magnetic Heterophase Photocatalyst. Mater. Lett. 2014, 118, 107-110. [CrossRef]

4. Kwon, Y.J.; Mirzaei, A.; Kang, S.Y.; Choi, M.S.; Bang, J.H.; Kim, S.S.; Kim, H.W. Synthesis, Characterization and Gas Sensing Properties of ZnO-Decorated MWCNTs. Appl. Surf. Sci. 2017, 413, 242-252. [CrossRef]

5. Gancarz, M.; Nawrocka, A.; Rusinek, R. Identification of Volatile Organic Compounds and Their Concentrations Using a Novel Method Analysis of MOS Sensors Signal. J. Food Sci. 2019, 84, 2077-2085. [CrossRef]

6. Rusinek, R.; Siger, A.; Gawrysiak-Witulska, M.; Rokosik, E.; Malaga-Toboła, U.; Gancarz, M. Application of an Electronic Nose for Determination of Pre-Pressing Treatment of Rapeseed Based on the Analysis of Volatile Compounds Contained in Pressed Oil. Int. J. Food Sci. Technol. 2019. [CrossRef]

7. Liu, H.; Zhu, W.; Han, Y.; Yang, Z.; Huang, Y. Single-Nanowire Fuse for Ionization Gas Detection. Sensors 2019, 19, 4358. [CrossRef]

8. Lavanya, N.; Sekar, C.; Anithaa, A.; Sudhan, N.; Asokan, K.; Bonavita, A.; Leonardi, S.; Neri, G. Investigations on the Effect of Gamma-Ray Irradiation on the Gas Sensing Properties of $\mathrm{SnO}_{2}$ Nanoparticles. Nanotechnology 2016, 27, 385502. [CrossRef]

9. Arshak, K.; Korostynska, O. Effect of Gamma Radiation onto the Properties of $\mathrm{TeO}_{2}$ Thin Films. Microelectron. Int. 2002, 19, 30-34. [CrossRef]

10. Arshak, K.; Korostynska, O.; Clifford, S. Screen Printed Thick Films of $\mathrm{NiO}$ and $\mathrm{LaFeO}_{3}$ as Gamma Radiation Sensors. Sens. Actuators A 2004, 110, 354-360. [CrossRef]

11. Arshak, K.; Korostynska, O. Preliminary Studies of Properties of Oxide Thin/Thick Films for Gamma Radiation Dosimetry. Mater. Sci. Eng. B 2004, 107, 224-232. [CrossRef]

12. Arshak, K.; Korostynska, O.; Henry, J. Thick Film pn-Junctions Based on Mixed Oxides of Indium and Silicon as Gamma Radiation Sensors. Microelectron. Int. 2004, 21, 19-27. [CrossRef]

13. Arshak, K.; Korostynska, O. Thin Films of $\left(\mathrm{TeO}_{2}\right)_{1-\mathrm{x}}\left(\mathrm{In}_{2} \mathrm{O}_{3}\right)_{\mathrm{x}}$ as Gamma Radiation Sensors. Sens. Rev. 2003, 23, 48-54. [CrossRef]

14. Arshak, K.; Korostynska, O. Gamma Radiation Dosimetry Using Tellurium Dioxide Thin Film Structures. In Proceedings of the IEEE Sensors 2002, Orlando, FL, USA, 12-14 June 2002; Volume 1, pp. 547-551.

15. Lu, X.; Zhou, L.; Chen, L.; Ouyang, X.; Liu, B.; Xu, J.; Tang, H. Schottky X-ray Detectors Based on a Bulk $\beta-\mathrm{Ga}_{2} \mathrm{O}_{3}$ Substrate. Appl. Phys. Lett. 2018, 112, 103502. [CrossRef]

16. Zhou, L.; Huang, Z.; Zhao, X.; He, Y.; Chen, L.; Xu, M.; Zhao, K.; Zhang, S.; Ouyang, X. A High-Resistivity ZnO Film-Based Photoconductive X-ray Detector. IEEE Photonics Technol. Lett. 2019, 31, 365-368. [CrossRef]

17. Katsumata, T.; Takeuchi, H.; Komuro, S.; Aizawa, H. X-ray Detector Based on Mn Doped $\mathrm{MgAl}_{2} \mathrm{O}_{4}$ and $\mathrm{Si}$ Photodiode. Rev. Sci. Instrum. 2018, 89, 095104. [CrossRef] 
18. Kim, J.-H.; Lee, J.-H.; Mirzaei, A.; Kim, H.W.; Kim, S.S. Optimization and Gas Sensing Mechanism of $\mathrm{n}-\mathrm{SnO}_{2}-\mathrm{p}-\mathrm{Co}_{3} \mathrm{O}_{4}$ Composite Nanofibers. Sens. Actuators B 2017, 248, 500-511. [CrossRef]

19. Kwon, Y.J.; Kang, S.Y.; Mirzaei, A.; Choi, M.S.; Bang, J.H.; Kim, S.S.; Kim, H.W. Enhancement of Gas Sensing Properties by the Functionalization of $\mathrm{ZnO}-$ Branched $\mathrm{SnO}_{2}$ Nanowires with $\mathrm{Cr}_{2} \mathrm{O}_{3}$ Nanoparticles. Sens. Actuators B 2017, 249, 656-666. [CrossRef]

20. Liang, G.; Sun, X.; Lai, J.; Wei, C.; Huang, Y.; Hu, H. Adding Lithium Fluoride to Improve the Electrochemical Properties $\mathrm{SnO}_{2} @ \mathrm{C} / \mathrm{MWCNTs}$ Composite Anode for Lithium-Ion Batteries. J. Electroanal. Chem. 2019, 853, 113401. [CrossRef]

21. He, J.; Wu, J.; Hu, S.; Shen, H.; Hu, X. A Low-Cost Flexible Broadband Photodetector Based on $\mathrm{SnO}_{2} / \mathrm{CH}_{3} \mathrm{NH}_{3} \mathrm{PbI}_{3}$ Hybrid Structure. Opt. Mater. 2019, 88, 689-694. [CrossRef]

22. Cho, C.J.; Pyeon, J.J.; Hwang, C.S.; Kim, J.S.; Kim, S.K. Atomic Layer Deposition of Ta-Doped SnO 2 Films $^{2}$ with Enhanced Dopant Distribution for Thermally Stable Capacitor Electrode Applications. Appl. Surf. Sci. 2019, 497, 143804. [CrossRef]

23. Kim, J.-H.; Mirzaei, A.; Bang, J.H.; Kim, H.W.; Kim, S.S. Selective $\mathrm{H}_{2} \mathrm{~S}$ Sensing without External Heat by a Synergy Effect in Self-Heated CuO-Functionalized $\mathrm{SnO}_{2}-\mathrm{ZnO}$ Core-Shell Nanowires. Sens. Actuators B 2019, 300, 126981. [CrossRef]

24. Zhong, X.; Shen, Y.; Zhao, S.; Li, T.; Lu, R.; Yin, Y.; Han, C.; Wei, D.; Zhang, Y.; Wei, K. Effect of Pore Structure of the Metakaolin-Based Porous Substrate on the Growth of $\mathrm{SnO}_{2}$ Nanowires and $\mathrm{Their}_{2} \mathrm{~S}$ Sensing Properties. Vacuum 2019, 167, 118-128. [CrossRef]

25. Gao, N.; Li, H.Y.; Zhang, W.; Zhang, Y.; Zeng, Y.; Zhixiang, H.; Liu, J.; Jiang, J.; Miao, L.; Yi, F.; et al. QCM-Based

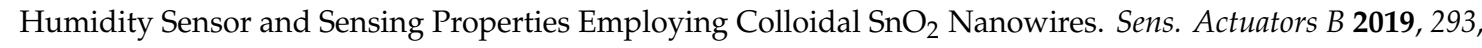
129-135. [CrossRef]

26. Ngoc, T.M.; Van Duy, N.; Hoa, N.D.; Hung, C.M.; Nguyen, H.; Van Hieu, N. Effective Design and Fabrication of Low-Power-Consumption Self-Heated $\mathrm{SnO}_{2}$ Nanowire Sensors for Reducing Gases. Sens. Actuators $B$ 2019, 295, 144-152. [CrossRef]

27. Chen, Y.; Qiu, W.; Wang, X.; Liu, W.; Wang, J.; Dai, G.; Yuan, Y.; Gao, Y.; Sun, J. Solar-Blind SnO $2 \mathrm{Nanowire}^{2}$ Photo-Synapses for Associative Learning and Coincidence Detection. Nano Energy 2019, 62, 393-400. [CrossRef]

28. Singh, M.K.; Pandey, R.K.; Prakash, R. High-Performance Photo Detector Based on Hydrothermally Grown $\mathrm{SnO}_{2}$ Nanowire/Reduced Graphene Oxide (rGO) Hybrid Material. Org. Electron. 2017, 50, 359-366. [CrossRef]

29. Suh, D.-I.; Byeon, C.C.; Lee, C.-L. Synthesis and Optical Characterization of Vertically Grown ZnO Nanowires in High Crystallinity Through Vapor-Liquid-Solid Growth Mechanism. Appl. Surf. Sci. 2010, 257, 1454-1456. [CrossRef]

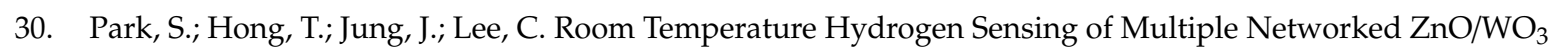
Core-Shell Nanowire Sensors under UV Illumination. Curr. Appl. Phys. 2014, 14, 1171-1175. [CrossRef]

31. Chinh, N.D.; Van Toan, N.; Van Quang, V.; Van Duy, N.; Hoa, N.D.; Van Hieu, N. Comparative $\mathrm{NO}_{2}$ Gas-Sensing Performance of the Self-Heated Individual, Multiple and Networked $\mathrm{SnO}_{2} \mathrm{Nanowire}_{\text {Sensors }}$ Fabricated by a Simple Process. Sens. Actuators B 2014, 201, 7-12. [CrossRef]

32. Kar, A.; Stroscio, M.A.; Meyyappan, M.; Gosztola, D.J.; Wiederrecht, G.P.; Dutta, M. Tailoring the Surface Properties and Carrier Dynamics in $\mathrm{SnO}_{2}$ Nanowires. Nanotechnology 2011, 22, 285709. [CrossRef]

33. Abideen, Z.U.; Kim, J.-H.; Kim, S.S. Optimization of Metal Nanoparticle Amount on $\mathrm{SnO}_{2}$ Nanowires to Achieve Superior Gas Sensing Properties. Sens. Actuators B 2017, 238, 374-380. [CrossRef]

34. Choi, S.-W.; Katoch, A.; Sun, G.-J.; Wu, P.; Kim, S.S. $\mathrm{NO}_{2}$-Sensing Performance of $\mathrm{SnO}_{2}$ Microrods by Functionalization of Ag Nanoparticles. J. Mater. Chem. C 2013, 1, 2834-2841. [CrossRef]

35. Park, J.Y.; Choi, S.-W.; Kim, S.S. Junction-Tuned $\mathrm{SnO}_{2}$ Nanowires and Their Sensing Properties. J. Phys. Chem. C 2011, 115, 12774-12781. [CrossRef]

36. Calestani, D.; Zha, M.; Salviati, G.; Lazzarini, L.; Zanotti, L.; Comini, E.; Sberveglieri, G. Nucleation and Growth of $\mathrm{SnO}_{2}$ Nanowires. J. Cryst. Growth 2005, 275, e2083-e2087. [CrossRef]

37. Wu, Y.; Yang, P. Direct Observation of Vapor-Liquid-Solid Nanowire Growth. J. Am. Chem. Soc. 2001, 123, 3165-3166. [CrossRef] 
38. Kim, S.; Bang, J.H.; Choi, M.S.; Oum, W.; Mirzaei, A.; Lee, N.; Kwon, H.C.; Lee, D.; Jeon, H.; Kim, S.S.; et al. Synthesis, Characterization and Gas-Sensing Properties of Pristine and $\mathrm{SnS}_{2}$ Functionalized $\mathrm{TeO}_{2} \mathrm{Nanowires}_{\text {. }}$ Met. Mater. Int. 2019, 25, 805-813. [CrossRef]

39. Kim, J.-H.; Kim, S.S. Realization of ppb-Scale Toluene-Sensing Abilities with Pt-Functionalized $\mathrm{SnO}_{2}-\mathrm{ZnO}$ Core-Shell Nanowires. ACS Appl. Mater. Interfaces 2015, 7, 17199-17208. [CrossRef]

40. Katoch, A.; Kim, J.-H.; Kwon, Y.J.; Kim, H.W.; Kim, S.S. Bifunctional Sensing Mechanism of $\mathrm{SnO}_{2}-\mathrm{ZnO}$ Composite Nanofibers for Drastically Enhancing the Sensing Behavior in $\mathrm{H}_{2}$ Gas. ACS Appl. Mater. Interfaces 2015, 7, 11351-11358. [CrossRef]

41. Schlesinger, T.; Toney, J.; Yoon, H.; Lee, E.; Brunett, B.; Franks, L.; James, R. Cadmium Zinc Telluride and Its Use as a Nuclear Radiation Detector Material. Mater. Sci. Eng. R Rep. 2001, 32, 103-189. [CrossRef]

42. Ahmadi, M.; Yeow, J.T. Fabrication and Characterization of a Radiation Sensor Based on Bacteriorhodopsin. Biosens. Bioelectron. 2011, 26, 2171-2176. [CrossRef]

43. Nava, F.; Bertuccio, G.; Cavallini, A.; Vittone, E. Silicon Carbide and Its Use as a Radiation Detector Material. Meas. Sci. Technol. 2008, 19, 102001. [CrossRef]

44. Owens, A.; Peacock, A. Compound Semiconductor Radiation Detectors. Nucl. Instrum. Methods Phys. Res. Sect. A 2004, 531, 18-37. [CrossRef]

45. Knoll, G.F. Radiation Detection and Measurement, 3rd ed.; John Wiley \& Sons. Inc.: New York, NY, USA, 2000.

(C) 2019 by the authors. Licensee MDPI, Basel, Switzerland. This article is an open access article distributed under the terms and conditions of the Creative Commons Attribution (CC BY) license (http://creativecommons.org/licenses/by/4.0/). 